\title{
A QUESTÃO DO ENSINO RELIGIOSO NA UNIÃO EUROPÉIA
}

\section{La cuestión de la enseñanza religiosa en los países de la Unión Europea}

\author{
Lílian Blanck de Oliveira ${ }^{1}$ \\ Sérgio Rogério Azevedo Junqueira ${ }^{2}$
}

\section{Resumo}

O Ensino Religioso é um componente curricular nas escolas do continente europeu desde o século dezoito, quando a religião passa a fazer parte do cotidiano escolar. A compreensão de um Ensino Religioso relacionado às instituições religiosas de matriz cristã persiste no século vinte e um, entretanto a alteração do perfil étinico-cultural religioso do continente está exigindo todo um repensar sobre esta prática curricular. O Fórum Europeu de Ensino Religioso, por meio de suas sessões ordinárias, está promovendo uma ampla reflexão sobre esta temática, buscando tecer novos olhares, leituras e perspectivas aos desafios que se apresentam na atualidade em relação a ela. O presente artigo explicita, a partir da Constituição da União Européia e atividades do Fórum Europeu de Ensino Religioso, alguns elementos históricos da geografia e itinerários pedagógicos desse componente curricular.

Palavras-chave: Educação; Ensino Religioso; Europa; Fórum Europeu do Ensino Religioso.

1 Doutora em Teologia - Área: Educação e Religião. Pedagoga e especialista nas Séries Iniciais do Ensino Fundamental e Educação Pré-Escolar. Coordenadora do Curso de Ciências da Religião - Licenciatura em Ensino Religioso e Curso de Pós-Graduação em nível de Especialização em Fundamentos e Metodologia de Ensino Religioso; professora colaboradora e pesquisadora no Programa de mestrado de Desenvolvimento Regional da Fundação Universidade Regional de Blumenau - FURB/SC.

2 Doutor em Ciências da Educação - Programa de Ensino Religioso pela Universidade Pontifícia Salesiana de Roma (Itália), Professor do Programa de Pós-Graduação em Educação da PUCPR, Líder do Grupo de Pesquisa Educação e Religião; Membro da Comissão de Capacitação Docente do Fórum Nacional Permanente do Ensino Religioso (FONAPER). 


\section{Resumen}

La enseñanza religiosa es un componente curricular en las escuelas europeas desde el siglo XIX, cuando esta disciplina entró a formar parte del sistema educativo.

La visión de la enseñanza religiosa como asignatura obrigatoria en las instituciones religiosas educativas cristianas persiste hasta hoy, en la Europa en el siglo XXI, mas, por otro lado, las alteraciones del perfil étnico, cultural e religioso del continente están exigiendo todo un nuevo planteamiento de esta práctica. El Forum Europeo de la Enseñanza Religiosa, en sus sesiones ordinarias, está promoviendo una amplia reflexión sobre este tema, buscando una nueva visión y perspectiva de frente a los desafíos presentados por las mudanzas arriba mencionadas. El presente artículo explicita, a partir de la Constitución de la Unión Europea y de las actividades del Forum Europeo de la Enseñanza Religiosa, algunos elementos históricos e certos itinerarios pedagógicos que ayudan a comprender el citado componente curricular.

Palabras clave: educación; enseñanza religiosa; Europa; Forum Europeo de la Enseñanza Religiosa.

A parte dois da Constituição da União Européia, em seu artigo setenta, explicita que todas as pessoas têm direito à liberdade de pensamento, consciência e religião. Este direito implica na liberdade do cidadão, entre outras questões, em mudar de religião ou de convicção religiosa; manifestar a sua religião ou a sua convicção individual ou coletiva em espaço público ou privado, pelo culto, ensino, práticas e celebração de ritos. Este direito à objeção de consciência é reconhecido pelas legislações nacionais que regem 0 respectivo exercício.

Do patrimônio cultural, religioso e humanista da Europa emanaram os valores universais que são os direitos invioláveis e inalienáveis da pessoa humana, bem como a liberdade, a democracia, a igualdade e o Estado de Direito. Os cidadãos europeus convencidos que sua comunidade após vivenciar historicamente ações dolorosas, possui na atualidade um desejo profundo de que todos possam atuar em prol da paz, da justiça e da solidariedade no mundo. Unidos na diversidade, os Estados pertencentes a esta comunidade compartilham a responsabilidade de garantir a todos os cidadãos o direito a possibilidades diferenciadas em suas opções, desde que não firam as questões fundantes do ser humano como a vida, a liberdade e as formas de expressões de cada um.

A questão religiosa é retomada duas vezes mais nos artigos oitenta e um e oitenta e dois da Constituição para garantir que a União Européia respeite a diversidade cultural, religiosa e lingüística, proibindo toda e qualquer forma de discriminação no campo cultural e religioso (Cf. Jornal Oficial $n^{\circ} \mathrm{C}$ 310 de 16 de dezembro de 2004). 
Por sua vez, a legislação da União Européia expressa uma "ausência de Deus" em seu preâmbulo, provavelmente porque a concepção sobre a idéia que se tenha de "Deus" apresente significados distintos para cada região e nação da Europa. Para os países do centro e do leste europeu, "Deus" é entendido como o espaço interior de cada ser humano, que resistiu à ingerência dos estados totalitários, ou seja, ao nazismo e ao comunismo.

Para os franceses, "Deus" significa a presença da Igreja Católica imiscuindo-se nos assuntos seculares e na relação do Estado com os cidadãos. Outro dado a ser citado é que desde a Reforma de Lutero, há na Europa uma idéia sobre "Deus" de confessionalidade católica, outra protestante ou huguenote. Esse fato historicamente remete às terríveis guerras envolvendo questões religiosas dos séculos XVI e XVII, fomento para práticas de fanatismo e a intolerância.

Para a comunidade mulçumana que hoje vive dentro dos Estados europeus (turcos, marroquinos, argelinos, tunisinos, etc...), estimada ao redor de quinze (15) milhões de pessoas, a menção do vocábulo "Deus" somente pode significar o Todo-Poderoso do cristianismo e não Alá e o seu Profeta; 0 que para eles acarreta numa ameaça ainda maior de perseguições e preconceitos do que já sofrem no momento. As pessoas que professam a fé islâmica são $7 \%$ da população na França e 2,7\% na Grã-Bretanha, oscilando de 1\% a 2\% nos demais estados europeus (GENRE, 2005).

Assim como existe a perspectiva do ingresso para a República da Bósnia e da Turquia, ambas as nações seguidoras do Profeta, os "Sábios" decidiram-se por acatar o princípio secularista francês porque se chegou à conclusão, baseada na História pregressa do continente, que a menção a "Deus" é um embaraço à Unidade Européia e não um bem que soma. Daí decorre 0 fato de não terem acolhido as campanhas orquestradas principalmente por organizações católicas a favor de "Deus na Europa".

Este é o cenário que circunscreve as discussões acerca do Ensino Religioso no continente europeu. É significativo fazer memória que este componente curricular foi estabelecido a partir da proposta de educação para as escolas do império austro-húngaro, onde a religião passou a fazer parte das disciplinas oferecidas aos estudantes europeus. Foi o resultado de uma nova concepção das relações religiosas em que Frederico II da Prússia (1740 a 1786), influenciado pelas idéias de Voltaire, permitiu liberdade de culto aos prussianos e tornou obrigatório o ensino básico, assim como a liberdade de expressão.

A revolução da educação nos últimos dois séculos produziu uma série de alterações em muitas direções e perspectivas. $\mathrm{O}$ ensino se generalizou e se tornou obrigatório até idades cada vez mais avançadas em muitos países e se diversificou significativamente em seus conteúdos. O próprio conceito de 
educação pode-se dizer que mudou. Na maioria dos países a educação aparece como uma das temáticas mais desafiantes para o futuro de seu desenvolvimento. Neste contexto, o Ensino Religioso é um componente curricular nas escolas do Brasil, que assume um novo perfil visando à formação dos estudantes, capaz de relerem o seu cotidiano em uma perspectiva pluralista, para que dele participem ativamente como cidadãos.

Neste cenário, o Ensino Religioso no Brasil também assumiu novas perspectivas como elemento do currículo escolar, sendo compreendido nos princípios da cidadania, do entendimento do outro enquanto outro e da formação integral do estudante. Muitas pessoas negam ser religiosas, entretanto é necessário registrar como um dado histórico, que toda pessoa de certa forma é "preparada" culturalmente para ser religiosa, do mesmo modo que é "preparada" para falar determinada língua, gostar disto ou daquilo, comer e/ou existir de uma forma. O ser religioso é um dado antropológico e cultural. No substrato de cada cultura sempre está presente o religioso (Cf. Jornal Oficial $n^{\circ}$ C 310 de 16 de dezembro de 2004).

No Brasil, os diferentes processos de ensino-aprendizagem que permeiam o componente curricular de Ensino Religioso partem sempre do convívio social dos estudantes para que se respeite a tradição religiosa que já trazem de suas famílias e assim se salvaguarde a liberdade de expressão religiosa de cada um. É no conhecimento e respeito mútuo que se cultiva a reverência ao Transcendente que é UM, mas também é MAIS pelas muitas formas de expressão nas diferentes culturas. Nesse contexto, o estudante terá oportunidades para desenvolver posturas de respeito e valorização em relação às diferenças religiosas, participando na construção de uma cultura de compreensão e entendimento mútuo, para a paz e fraternidade planetánias (FONAPER, 1997).

A atual concepção de Ensino Religioso ao orientar-se para a definição do cerne deste componente curricular, ou seja, o RELIGIO; assumiu a visão original dele: RELEGERE (reler), na releitura do fenômeno religioso a partir do convívio social dos alunos, que constitui objeto de estudo e conhecimento na diversidade cultural religiosa do Brasil, sem erigir uma ou outra forma de religiosidade (JUNQUEIRA, 2000, p.54).

O conceito de Ensino Religioso a partir do religare pode encaminhar para um proselitismo, visto que se constitui também no entendimento da vivência de valores da ética religiosa na ótica ocidental. Considerar a relação horizontal de fraternidade como sendo o princípio fundamental e justificadamente do Fenômeno Religioso é inaceitável a partir, por exemplo, de uma postura rigorosamente teocêntrica. A solidariedade humana é um epígono de conduta, periférico em relação ao experienciar transcendente/imanente de uma consciência taoista, hinduísta ou islâmica, por exemplo. 
Comparando-se o fenômeno religioso com o fenômeno social ou similar, pode-se dizer que se designa a estrutura especial do ser humano definido por sistema de relações com os outros seres humanos. Poder-se-ia descrever o fenômeno religioso como um mundo de estrutura estritamente relacional? Mas como ou com quem o homem relaciona-se na religião? No fundo de toda a situação verdadeiramente religiosa, encontra-se a referência aos fundamentos últimos do ser humano: quanto à origem, quanto ao fim e quanto à profundidade. $\mathrm{O}$ problema religioso toca o homem em sua raiz ontológica. Não se trata de fenômeno superficial, mas implica a pessoa como um todo. Pode caracterizar-se o religioso como zona do sentido da pessoa. Em outras palavras, a religião tem a ver com o sentido último da pessoa, da história e do mundo.

Para compreender o atual perfil do Ensino Religioso no continente europeu, é interessante estabelecer a idéia de Europa, que em sua diversidade de línguas e de tradições constitui uma realidade desde o tempo de Carlos Magno, quando esse continente tornou-se a "Res publica christiana". Não é possível compreender a história do homem e da mulher do Ocidente sem essa região do planeta, que interferiu de forma significativa nas Américas, Ásia, África e Oceania (GENRE; PAJER, 2005, p.20-21).

A Europa sobreviveu a inúmeras batalhas, sendo que a mais recente, em termos globais, foi a II Guerra Mundial. Em 1929, nasceu a idéia de uma UNIÃO EUROPÉIA, com o ministro do exterior francês Aristide Briand, idéia que foi retomada em 1941, com o manifesto "Por uma Europa Unida e Livre", publicado pelos italianos Altiero Spinelli e Ernesto Rossi. Entretanto, a proposta tornou-se realidade pelo tratado de Maastricht: "Tratado sobre a União Européia", publicado em fevereiro de 1992.

O Conselho Europeu desde sua criação no campo da educação procurou reforçar a sensibilidade de seus Estados membros pela busca do conhecimento e respeito das diferenças, como fator de força, a fim de chegar a um sentido de comunidade. A multiplicidade cultural não foi um problema, mas algo com significativa importância. A escola, assim como os meios de comunicação, passaram a ser espaços de difusão para essas idéias.

A União Européia geograficamente localiza-se entre o Peloponeso ao Círculo Polar Ártico, com aproximadamente três milhões de quilômetros quadrados, uma população cerca de 371 milhões de pessoas e onze línguas oficiais. No que se refere ao campo religioso, as estatísticas apontam a existência de 58,40\% de católicos, 18,40\% de protestantes de diversas Igrejas, 11\% anglicanos, 2,70\% gregos-ortodoxos, $2 \%$ de muçulmanos, $0,04 \%$ de hebreus, $7,50 \%$ que se dizem sem religião (GENRE, 2005).

Nesse contexto, a escola passa a assumir posições que antes pertenciam a outras instituições, como a família. Por exemplo, na formação de valo- 
res, a escola de alguma forma passou a ser encarregada de orientar a formação das novas gerações: educar para a convivência democrática, promover 0 respeito aos direitos humanos, desenvolver a consciência da multiplicidade dos valores, sensibilizar para a necessidade de prevenir todas as formas de agressões, tomar posição sobre o problema da migração, aprender a dominar novas línguas, conhecer novas culturas e respeitar as diversas formas de opção religiosa.

A questão do Ensino Religioso nesse contexto é muito complexa. Na realidade a Europa, já no final do século XIX, iniciou um movimento de novo referencial para a questão da educação religiosa, não focalizando somente 0 conteúdo doutrinal, mas também o sujeito, o processo pedagógico. Nos países de língua alemã surgiu a pedagogia religiosa - Religionspädaggik. O primeiro a ocupar-se dessa nova situação foi Joseph Göttler (1874-1935), sendo considerado o fundador da pedagogia da religião, como ciência autônoma, um expoente do Método de Munique, trabalhando com o referencial pedagógico de Herbart.

Outro nome significativo foi, com certeza, Otto Willamann, pedagogo que organizou os conteúdos segundo a base da psicologia das idades. Foi por mais de vinte anos o diretor da Katechetische Bläter (DKV), órgão oficial da Associação Catequética Alemã, que nasceu em Munique em 1887, com a preocupação básica da pedagogização dessa área do conhecimento religioso.

A posição sobre a questão religiosa assume novas perspectivas, como se o homem e a mulher europeus buscassem algo para dar sentido à sua vida, mas o que não significa necessariamente que pertençam e/ou queiram pertencer a uma instituição religiosa, fato que está promovendo uma alteração na relação das Igrejas com o Estado. Esse posicionamento torna-se complexo exatamente pela longa história religiosa desses países. De forma geral o modelo empregado é o confessional cristão em que a Igreja orienta os trabalhos, independendo da confessionalidade dos cidadãos, sejam eles católicos, ortodoxos ou protestantes.

Os países de confissão católica são particularmente os localizados ao sul da Europa e historicamente já assumem este perfil religioso, ou seja: Portugal, Espanha, França, Bélgica, Itália, Malta e Áustria. Neste grupo, encontramse ainda a Irlanda e a Polônia. Os países de orientação protestante vão do Reino Unido ao da região báltica e da Tchecoslováquia até os países da região Escandinávia, e Alemanha. Na região oriental de cultura eslava situam-se os países de tradição ortodoxa como a Grécia, Chipre e Países Bálcãs.

Esta identidade está articulada nos países por meio de relações junídicas entre Estado e Igreja, que condicionam fortemente o perfil legal e conteúdo do Ensino Religioso. A disciplina se apresenta com diferentes perfis como o modelo separatista, típico da França e da Eslovênia, onde por lei não pode 
ter o Ensino Religioso propriamente dito nas escolas públicas; o modelo concordatário onde vários países possuem a compreensão que o Ensino Religioso encontra-se em um acordo entre as igrejas cristãs e os Estados, garantindo segundo eles uma parte da identidade da própria tradição religiosa e ao mesmo tempo uma certa neutralidade estatal, sobretudo o direito da liberdade das famílias e dos alunos; o modelo integrado, típicos dos Estados que possuem uma ligação histórica privilegiada com igrejas em particulares como o Reino Unido com a igreja Anglicana; os países escandinavos com a tradição evangélico-luterana; a Grécia e o Chipre com a Igreja Ortodoxa, nestes casos as religiões ensinadas são consideradas como cultura nacional mais do que como catequese, estão integradas com as diversas disciplinas escolares e são mais ou menos obrigatórias para todos.

Num cenário prioritariamente cristão, o continente vivencia uma nova situação, ou seja, a entrada de um grande número de religiões com perfis diferenciados, promovendo iniciativas de reformas no sistema escolar. O movimento de mudança advém das próprias escolas, provocadas por reações dos estudantes com essas novas sensibilidades.

A Bélgica flamenga publicou um documento em 1997 sobre o Ensino Intercultural, um desafio lançado à catolicidade da escola, tematizando a diferença da cultura e da tradição religiosa dos estudantes. Para incrementar a educação, a Inglaterra, por meio dos Bispos, também apresentou em seu texto "Catholic Schools and other Faiths - 1997", reflexões sobre o pluralismo cultural presente nas escolas católicas, não menos nas anglicanas, ou públicas, discutindo a necessidade de uma informação inter-religiosa, assim como abrindo espaços/tempos/lugares para os estudantes se aproximarem de sua fé.

Na Alemanha, pelo contrário, a Conferência Episcopal lançou o texto "Die bildende Kraft des Religionsunterrichts", 27 de setembro de 1996, reforçando a necessidade irredutível da confessionalidade no Ensino Religioso. Entretanto, por iniciativa de um dos Estados alemães: Brandeburgo, o Parlamento Regional instituiu no ano de 1997 uma disciplina nova: "Ciência da Vida, Ética e Religião" (em alemão LER), com o objetivo de assegurar uma base para uma concepção da vida inspirada nos valores, no conhecimento da tradição ético-filosófica e para a formação do juízo moral, não sem o conhecimento da religião e visão do mundo.

A decisão contrastou sobre o plano jurídico e pedagógico da autoridade católica, evangélica e do partido democrático-cristão. Foi motivado pela grande maioria dos estudantes sem nenhuma pertença religiosa e pais ateus que nasceram e cresceram no clima anti-religioso da Alemanha democrática.

Tal proposta não exime nem proíbe que as paróquias cristãs realizem seu trabalho com os batizados. Caso parecido está acontecendo na Áustria. Os estudantes que não querem o Curso de Religião Católica de oferta obrigatória 
podem escolher um Curso de Ética ou de Educação aos Valores, dirigidos por professores de Filosofia. Na Espanha, desde 1994, o Ministério da Educação já tinha sugerido uma disciplina alternativa ao Ensino Religioso no Ensino Médio denominada "Sociedade, cultura e religião", que propõe elementos de história da religião de origem hebraico-cristã, da cultura e de história do cristianismo com fundamentação ética.

Luxemburgo, Bélgica e Estados Alemães oferecem aulas de ética não confessional, como matéria alternativa. Na Holanda, foi introduzido um estudo comparado das diversas filosofias de vida, religiosas ou não. A Inglaterra propõe um ensino obrigatório transconfessional e nos países escandinavos um ensinamento histórico-objetivo de tradição luterana.

Busca-se compreender como essas disciplinas de aspecto-religiososimbólico e cultural critico já existentes poderão contribuir no que se refere ao problema religioso. Somente os franceses permanecem fora desse processo, pois por lei não é permitido nenhum tipo de Ensino Religioso. Com isso, o analfabetismo na área do conhecimento religioso está crescendo, o que impede que muitos compreendam a própria cultura européia.

Na França, a situação apresenta tal seriedade que o Ministério da Educação e da Cultura, em 1997, realizou Seminários em colaboração com a Escola de Louvre sobre a temática: Formação à dimensão religiosa e ao patrimônio cultural, como busca de uma cultura religiosa interdisciplinar.

A Europa, na atualidade, apresenta-se como um mosaico a desafiar novas organizações em seus desenhos, uma vez que mais do que em qualquer outro continente do Ocidente, a religião e a cultura estão estritamente interligadas. Ao mesmo tempo em que cresce a indiferença pela instituição religiosa formal, é notória a busca por um novo sentido de vida.

Para discutir este componente do currículo escolar foi criado o Fórum Europeu para o Ensino Religioso (1984), que oportuniza um encontro de Professores dos diversos segmentos da Escola Elementar e Média, Pesquisadores, Professores das Universidades para formação de Docentes e Autores de livros para essa área do conhecimento. Esses integrantes são católicos e, como grupo, sentem dificuldades em abrir o Fórum numa perspectiva ecumênica. Reúnem-se a cada dois anos, com o objetivo de partilhar as diversas realidades de seus países, aprofundar temas previamente estabelecidos e indicar pesquisas em nível local e/ ou continental.

A proposta de criar esse espaço de discussão e reflexão foi inspirada em uma atividade já existente, que é o Fórum de Catequetas (Especialistas em Catequese), que se encontram desde 1950.

Já foram realizadas onze (11) sessões do Fórum Europeu de Ensino Religioso nos últimos vinte (20) anos: 


\begin{tabular}{|c|c|c|c|}
\hline I Sessão & 1984 & $\begin{array}{l}\text { França / } \\
\text { Kingenthal }\end{array}$ & $\begin{array}{l}\text { O Ensino Religioso para os alunos } \\
\text { do Ensino Médio nos países euro- } \\
\text { peus. }\end{array}$ \\
\hline II Sessão & 1986 & $\begin{array}{l}\text { Alemanha / } \\
\text { Munique }\end{array}$ & $\begin{array}{l}\text { O professor de Ensino Religioso } \\
\text { como acompanhador dos alunos } \\
\text { do Ensino Médio na Europa. }\end{array}$ \\
\hline III Sessão & 1998 & $\begin{array}{l}\text { Luxemburgo/ } \\
\text { Luxemburgo }\end{array}$ & $\begin{array}{l}\text { O Ensino Religioso diante do pro- } \\
\text { blema do senso da vida. }\end{array}$ \\
\hline IV Sessão & 1990 & $\begin{array}{l}\text { Dinamarca/ } \\
\text { Slaglese/ } \\
\text { Copenhague }\end{array}$ & $\begin{array}{l}\text { O Ensino Religioso na Europa en- } \\
\text { tre a democracia e a secularização. }\end{array}$ \\
\hline V Sessão & 1992 & Áustria/ Graz & $\begin{array}{l}\text { O Ensino Religioso, serviço da Igre- } \\
\text { ja na unificação da Europa. }\end{array}$ \\
\hline VI Sessão & 1994 & Espanha/ Adri & $\begin{array}{l}\text { O Ensino Religioso diante o desa- } \\
\text { fio do pluralismo cultural na Euro- } \\
\text { pa. }\end{array}$ \\
\hline VII Sessão & 1996 & Itália/ Brixen & $\begin{array}{l}\text { Identidade e diálogo: requisitos } \\
\text { para um Ensino Religioso na Euro- } \\
\text { pa. }\end{array}$ \\
\hline VIII Sessão & 1998 & Portugal/ Lisboa & $\begin{array}{l}\text { A relação do Ensino Religioso e sua } \\
\text { finalidade educativa na escola. }\end{array}$ \\
\hline IX Sessão & 2000 & $\begin{array}{l}\text { Áustria/ } \\
\text { Bratislavia }\end{array}$ & $\begin{array}{l}\text { Qual a competência religiosa den- } \\
\text { tro de uma Europa multicultural? }\end{array}$ \\
\hline X Sessão & 2002 & $\begin{array}{l}\text { Alemanha/ } \\
\text { Dresden }\end{array}$ & $\begin{array}{l}\text { Ensino Religioso como construção } \\
\text { da identidade de uma personalida- } \\
\text { de e a dimensão social. }\end{array}$ \\
\hline XI Sessão & 2004 & Itália/ Carini & $\begin{array}{l}\text { Confissão cristã e religiões mono- } \\
\text { teístas por uma nova cidadania eu- } \\
\text { ropéia }^{1} \text {. }\end{array}$ \\
\hline
\end{tabular}

${ }^{1}$ PAJER, F. Lê Foum Européen de l'enseignement religieux 1984-2004: vingt ans de cheminement. Vers où? Mimeo: Rome, 2004. 
Algumas sessões mais recentes estão procurando estabelecer de fato o Ensino Religioso dentro do contexto da educação, como, por exemplo, a VIII Sessão ocorreu em Portugal (Lisboa), de 03 a 07 de junho de 1998. 0 tema do encontro foi: A contribuição do Ensino Religioso na ação educativa da escola na Europa na proximidade do terceiro milênio. Foram apresentados trabalhos pelos seguintes especialistas: o sociólogo da Universidade de Lisboa, José Machado Pai, o professor Jean Kerkhofs, da Universidade Católica de Louvain, e o filósofo Abilio De Gregorio, de Madri.

Dentre as muitas pesquisas apresentadas nesse encontro, o primeiro dado significativo se refere ao novo jovem europeu, pois são em torno de 83 milhões os estudantes que freqüentam da educação infantil à Universidade. Na Europa, as crianças são colocadas cada vez mais jovens na escola, em consequiência da ausência cada vez maior da família. Outra característica é o aumento cada vez maior do período obrigatório de permanência do estudante - escolaridade obrigatória, ao menos até 16 anos ou mais. Existe uma redução da população na escola elementar, assim como uma duplicação da população universitária. No período de 75 a 95, a escola elementar caiu de 29 milhões para 22 milhões; na Universidade, cresceu de 5 milhões e meio para 10 milhões (GENRE, 2005).

Nesse contexto, presencia-se uma recomposição do religioso em todo o Ocidente pós-moderno. Tal visão está embasada em duas pesquisas comentadas no Fórum: "Fondazione European Values Study" (1981) e outra do sociólogo suíço Roland Campiche (1991). Na escola, assiste-se a uma rápida evolução dos valores éticos de uma geração a outra. Em lugar de valores tradicionais, surgem novos valores. A família, em conseqüência de suas necessidades, está cada vez mais ausente na vida dos filhos. A transmissão de valores, assim como da educação religiosa, quando esta ocome, é repassada a outros espaços.

Ao mesmo tempo em que se percebe uma grande sede de espiritualidade, identifica-se também a presença de uma multirreligiosidade, que busca por espaços religiosos, que auxiliem a encontrar uma resposta para as questões existenciais de homens e mulheres. 0 nomadismo espiritual e o sincretismo religioso fragmentam e inibem a pertença religiosa. A própria imagem de Deus se desenvolve de forma diversa nesses jovens pós-cristãos, em direção a um divino sem rosto e sem nome, como uma mística cósmica, do tipo New Age, onde todas as religiões se equivalem.

O documento final dessa Sessão do Fórum Europeu de Ensino Religioso apresenta que os jovens participam das aulas de Ensino Religioso e mesmo quando declaram não serem religiosos, na verdade, estão à procura de um sentido para as suas vidas, estão carentes de uma espiritualidade. Percebe-se cada vez mais a necessidade de distinguir a disciplina de Ensino Religioso da Catequese e ajudar os jovens em suas questões existenciais. 
Outra questão a ser compreendida é o contexto pluralista étnicoreligioso em que a Europa está envolvida. A XI Sessão do Fórum Europeu de Ensino Religioso ocorreu entre os dias 14 a 18 de abril de 2004, na cidade de Carini (Sicília/Itália), com a presença de aproximadamente cinqüenta pessoas, entre professores da educação básica e do ensino superior; editores e pesquisadores vindos de quinze países do continente europeu, a saber: Itália, França, Espanha, Alemanha, Portugal, Bélgica, Suíça, Áustria, Grécia, Tchecoslováquia, Romênia, Hungria, Croácia, Lituânia, Eslovênia e do Brasil como convidado o Professor Dr. Sergio Rogério de Azevedo Junqueira. O tema da discussão foi: Confissão cristã e religiões monoteístas por uma nova cidadania européia.

O evento ocorreu em um contexto em que a Educação européia urgia em ser reavaliada, e um novo repensar se dá igualmente em relação ao Ensino Religioso, como elemento escolar formador e educativo. Em vários países da Europa que fazem parte da União Européia esse componente curricular assume um perfil confessional, que progressivamente vem assumindo uma identidade cultural e histórica e orienta a organização do Ensino Religioso, para que este seja coerente com o rosto pedagógico da concepção pedagógica dos diferentes países daquela comunidade.

Percebe-se a reflexão do Ensino Religioso caminhando para ser estruturada sob a égide de três princípios: finalidade da escola; liberdade de consciência dos alunos e o respeito ao patrimônio religioso das comunidades.

A discussão sobre a identidade do Ensino Religioso no continente europeu e suas diferentes relações ocorreu por meio de vários pontos de vista: político (Dr. Fernando Alvarez de Miranda y Torres - Embaixador da Espanha); jurídico (Prof. Dr. Manfred Baldus - Univ. de Colônia/Alemanha) e religioso (Prof. Roland Biewald - Univ. Dresden/Alemanha). Assim como de especialistas de Tradições Cristãs: Anglicano (Dr. John Flack - Bispo Anglicano/ Diretor do Centro Anglicano em Roma); Ortodoxo (Prof. Constantino Cucos Unv. De Iari/Romênia) e Católico (Profa. Dra. Chiara C. - Univ. Roma Três/ Itália).

O Ensino Religioso no continente europeu torna-se complexo, diante de uma comunidade historicamente difícil, em virtude do processo de secularização, da redução da população dos países de origem, bem como pelo aumento de uma nova juventude de imigrantes, especialmente os mulçumanos. Em razão desses aspectos, há que se criar um novo perfil para o Ensino Religioso.

Nesse sentido, o Prof. Piero Stefani (Instituto Ecumênico de Veneza/ Itália), provocou uma discussão sobre a ligação entre as relações monoteístas, com forte presença nos países de fundamento cristão, hebreu e mulçumano. Ao mesmo tempo não é possível esquecer que na Europa se encontram 
grupos de indiferentes no sentido religioso, o que exige um posicionar-se dos que discutem o Ensino Religioso no contexto europeu.

Um rico momento ao longo do Fórum foram as comunicações das diferentes realidades: Artacho, R. (Espanha) - Teoria construtivista no conhecimento como base para o Ensino Religioso na situação do diálogo inter-religioso; Barre, C. (Suíça) - Pesquisa realizada em 2003 sobre o Ensino Religioso nos países europeus: A ciência da religião como disciplina escolar no Ensino Médio; Bonaiuti, R. (Itália) - Um projeto de currículo de Ensino Religioso transconfessional; De Carli, S. (Itália) - A reforma da escola na Itália e a hipótese por um futuro do Ensino Religioso na escola; Matos, R. (Portugal) - A bíblia na manuscrita jovem; Noreerilhat, R. (França) - Pedagogia da cultura religiosa na França; Rugeviviuti, G. (Lituânia) - A situação do Ensino Religioso na Lituânia; Zoggraphos, M. (França) - O ensino do fato cultural na escola secundária pública na Espanha novo currículo Sociedade Cultura e Religião; Hisch, J. (Áustria) - Projeto ecumênico no sistema escolar austríaco; Muchova, L (Tchecoslováquia) - O Ensino Religioso inter-religioso na República Tcheca; Smahul, R. (Tchecoslováquia) - Ajuda à família cristã. Como convidado o Prof. Dr. Sérgio Junqueira (Brasil) apresentou A construção histórica do modelo brasileiro de Ensino Religioso.

A reflexão em nível internacional nesse fórum demonstrou que 0 Ensino Religioso somente contribuirá no desenvolvimento das crianças e jovens se estes puderem compreender a sua própria Tradição Religiosa e se for criado um clima de respeito e reconhecimento entre os cidadãos; com suas tradições e etnias em todos os campos da cultura, inclusive a religiosa.

Ao mesmo tempo, notou-se a necessidade e por que não a urgência de que o Ensino Religioso se torne objeto de estudos sistemáticos, de um processo pedagógico de reflexão para que se sustente como um componente curricular.

Para divulgar o processo de reflexão no continente europeu foi criado o EuForNews - boletim distribuído por e-mail pela Coordenação do Fórum Europeu do Ensino Religioso informando do movimento continental deste componente curricular.

\section{Considerações}

A presença de diversas culturas com suas diferentes expressões de ordem lingüística, artística, religiosa, etc., numa sociedade e sistema educacional, exigem uma tomada de consciência, uma nova reflexão sobre os encaminhamentos e elaboração de suas leis maiores assim como de suas diretrizes curriculares. 
Uma das muitas diferenças presentes no contexto educacional está relacionada com a questão religiosa, originada na diversidade cultural própria dos diferentes grupos de humanos. Ela envolve toda uma gama de relações, interações e conexões, associada a outras questões, que movem, facilitam ou emperram o processo educativo como um todo.

A discussão sobre o Ensino Religioso progressivamente tem assumido espaço na escola, sendo articulado a partir da estrutura escolarizada da sociedade ocupando-se em considerar a perspectiva da cidadania como 0 sentido da identidade cultural e das tradições locais, ao mesmo em que se apóia na diversidade interna dos países. O processo de escolarização do Ensino Religioso articulado aos demais componentes curriculares presentes no cotidiano educativo poderá contribuir na condução ao respeito e atenção ao outro, a um sentido e exercício de responsabilidade social.

Diferentes pesquisas e estudos trazem dados irrefutáveis que reclamam por novas leituras e práticas pedagógicas que respondam aos anseios dos estudantes em relação às questões que circunscrevem o cotidiano humano e, por conseguinte, o cotidiano escolarizante na área do religioso, seja numa perspectiva de contexto cultural e/ou existencial.

\section{Referências}

AERENS, L. Sixième Forum européen de l'enseignementreligieux (du 06 au 10 avril 1994) - Madrid. L'enseignement religeux face aux défis de la pluralité culturelle en Europe. Lumen Vitae, v.4, n.49, p. 450-451, 1994.

ALBERICH, E. L'insegnamento scolastico della religione in Europa: il III Forum Europeo (Lussemburgo, 21-24 ottobre 1998). Orientamenti Pedagogici, v. 214, n. 36, p. 420-424, 1989.

ARRIGHINI, A. Le diverse giustificazioni dell'IRin Europa. Il Regno-Attualità, v.10, n. 35, 290-292, 1990.

BRAIDO, P. Lineamenti di storia della catechesi e dei catechismi. Rome: UPS. 1989.

CARMINATI, M. Um trentennio di storia della catechesi italiana (1900-1930). Torino: Elle Di Ci. 1995.

GENRE, E.; PAJER, F. L'Unione Europea e la sfida delle religioni: verso uma nuova presenza della religione nella scuola. Torino: Claudiana, 2005.

Jomal Oficial $n^{\circ}$ C 310 de 16 de Dezembro de 2004. Disponível em: http:// europa.eu.int/eur-lex/lex/pt/treaties/dat/12004V/htm/12004V.html. Acessado em 15 nov. 2005. 
JUAN PABLO II. Discurso al Simposio del Consejo de las Conferencias Episcopales de Europa sobre la Enseñanza Religiosa en la escuela pública. Actualidad Catequética, v.151, p. 645-652,1991.

LAENG, M. Insegnamento della Religione Cattolica e pluralismo: divergenze e convergenze. Orientamenti Pedagogici, v.267, n. 45, p.466-470, 1998.

MANTELLINI, G.; VALENTE, D. Moduli di economia \& diritto, lezioni e problemi. Rome: Mondadori, 1998.

PAJER, F. (ed.). L'insegnamento scolastico della religione nella Nuova Europa. Torini: Elle Di Ci, 1991.

PAJER, F. Breve storia del Forum Europeo. Rome: Mimeo, 1998.

PAJER, F. Catechesi, insegnamento o etica? Il Regno: Attualità, v.20, n. 35, p. 605-607, 1990.

PAJER, F. Cultura Religiosa nouvelle laicitè. Il Regno: Attualità, v.14, n. 43, p. 440-442, 1998.

PAJER, F. Le teorie pedagogiche dell'Educazione Religiosa. In: RELIGIO: Enciclopedia temática della Educazione Religiosa. Casale Monferrato: PIEMME, 1998. p. 280-282.

VVAA. Conclusiones del Simposio Europeo sobre la Enseñanza de la Religion Católica en la Escuela Pública (Roma, 13-15 de abril de 1991). Actualidad Catequética, v.151, p. 653-655, 1991.

Recebido em: 06 set. 2005 Aceito em: 17 nov. 2005 